\title{
QUANTIFICATION OF HERBICIDE SPRAY DEPOSIT VARIATION FOLLOWING AERIAL APPLICATION IN FORESTRY OPERATIONS
}

\author{
B. RICHARDSON, J. RAY and A. VANNER
}

NZ Forest Research Institute, Private Bag 3020, Rotorua, New Zealand

\section{SUMMARY}

High levels of spatial deposit variation can be expected during aerial herbicide applications in forestry situations. In a typical application, less than $20 \%$ of the sprayed area is likely to receive a herbicide dose within $10 \%$ of the application rate. This estimate is influenced by the size (i.e. area) of individual samples. Of the factors considered, error in locating and maintaining the correct track along a flight line is probably the largest contributor to high levels of spatial variability of spray deposition. Although pilots are able to maintain a consistent air speed, their instrumentation does not give a reliable indication of ground speed. Other factors which also contribute to increased spray deposit variation are flying height, wind speed and wind direction.

Keywords: aerial application, herbicide, spray deposition, deposit variation, flying speed.

\section{INTRODUCTION}

An efficient herbicide application requires that the minimum quantity of chemical required to achieve the biological objective is distributed evenly over the target area. An even spray distribution is necessary because as the distribution becomes more erratic, there is an increase in the proportion of the area which is either overdosed or underdosed. This represents an economic loss because chemical applied at higher than necessary rates is wasted, whereas in areas which receive sub-lethal doses, weed control is poor and the crop can suffer from intense competition.

Spray deposit variation is often expressed using the coefficient of variation (CV) which is calculated as:

CV $(\%)=$ standard deviation in deposition $\times 100 /$ mean deposition

A generally accepted maximum level of deposit CV is $30 \%$ (Parkin and Wyatt 1982; Spillman 1980).

Using data from numerous operational field trials, this paper illustrates that high levels of deposit variation can be expected during aerial herbicide applications in forestry situations. Results of trials to evaluate the accuracy with which aircraft can follow pre-marked flightlines and maintain the requested flying speed are also presented to assess the likely impact of these factors on deposit variation.

\section{Herbicide deposit variation}

\section{METHODS}

Spray deposition data were collated from six aerial application trials, incorporating sixteen separate treatments, conducted during the 1980s. During these trials, aircraft (mainly helicopters) flew multiple swath patterns over the spray blocks and applied herbicides under variable operating and meteorological conditions. Treatment blocks were usually at least 1 ha in area. The range of treatments and conditions encountered during these trials has resulted in a database of over 2,000 records which is representative of most aerial herbicide applications practiced in New Zealand forestry. The trials deposition data were collected using various types of spray collectors, including foliage and other three-dimensional artificial collecting surfaces. However, for consistency only two-dimensional artificial collecting surfaces, usually

Proc. 46th N.Z. Plant Protection Conf. 1993: 319-324 
about $100-150 \mathrm{~cm}^{2}$ in area, were used in the analyses. Previous studies have shown that the sampling and analytical methods utilised during these trials do not give significantly different results (Richardson et al. 1989).

All deposit data were expressed as percentage recoveries and then normalised so that the average deposit for each treatment was $100 \%$. This ensured that variation between treatments did not contribute to the estimate of deposit variation. The CV in deposition was calculated for individual treatments and for the entire dataset. Several transformations were tested for their ability to stabilise the variance and to achieve normality for the deposit distribution, as indicated by the Kolomogorov-Smirnov statistic (Zar 1984).

\section{Flying accuracy}

Two trials were conducted in the mid-1980s under low-wind, cool conditions on flat, rectangular spray blocks, approximately 1.7 and $0.9 \mathrm{~km}$ long. Both sites were covered with a patchy distribution of grass and logging debris. The flight lines were pre-marked at each end of the blocks and then flagged with flagmen during the operation. The actual position of the aircraft was marked with numbered cards as it passed overhead in the centre of the spray block so that comparisons could be made of expected and actual lane separation. In the first trial $(1.7 \mathrm{~km}$ block), a Squirrel helicopter flew 58 flight lines. In the second (1.0 km block), an AgCat (fixed wing), a Jet Ranger and a Squirrel were compared using 84, 54, and 48 flight lines respectively.

Flying speed

Two trials were conducted in the mid-1980s to test the ability of a pilot to fly at the requested groundspeed and to examine the effectiveness of normal aircraft speedmeasuring instrumentation.

In Trial 1, a Bell 206 Jet Ranger was fitted with a doppler radar speed monitoring device (KR-10SP, Kustom Electronics Inc, Kansas, USA) to give a direct measure of groundspeed. At Rotorua airport the aircraft was flown along a premarked flightline of $1000 \mathrm{~m}$ at requested speeds of $28,56,83$, and $111 \mathrm{~km} / \mathrm{h}$, with the pilot using the indicated airspeed (pitot tube) to gauge his speed, as in a normal spraying operation. Each speed run was replicated four times. During each run, the indicated airspeed and radar groundspeed were recorded at frequent intervals by observers in radio contact with the pilot, and an average speed was calculated. The time taken to fly each 1000 $\mathrm{m}$ run was measured by observers with stopwatches and the "best" estimate of actual groundspeed was calculated from this information. Differences among the various measures of speed were examined using analysis of variance.

Trial 2 was conducted during establishment of an operational grass releasing trial in Kaingaroa Forest. The time taken for each of three aircraft (Squirrel, Jet Ranger and AgCat) to spray a number of flight lines $(870$ to $890 \mathrm{~m})$ was measured using stopwatches. The aircraft were flown in a back-and-forth pattern and data for each direction were kept separate. The calculated mean groundspeeds for each flight direction were compared with the requested speed.

\section{Herbicide deposit variation}

\section{RESULTS}

To simplify the calculation of the proportion of the sprayed block which receives a given herbicide dose, it is important to meet the assumptions of a stable variance and a normal distribution of deposit data. The raw data met neither of these assumptions, and a natural $\log$ transformation was required to stabilise the variance across all trials and treatments. Following this transformation, the distribution of spray deposits was found to be significantly different from a normal distribution based on the KilomogorovSmirnov statistic. On closer examination of the data (Fig. 1), however, it was clear that although the distribution was negatively skewed, the deposit data closely approximated to a normal distribution following a logarithmic transformation. Although a square root transformation resulted in data which conformed more closely to a normal distribution, in this case the variance of the deposit values were not stabilised as well 
as with a log transformation. On balance, it would appear that a log transformation was most appropriate.

Over the range of treatments within the normalised database, the CV of spray deposition varied from 27 to $71 \%$, with an overall mean value of $43 \%$. Thus, the generally accepted maximum CV of $30 \%$ was almost always exceeded. Based on calculations using normal probability tables, this result suggests that on average, a typical sprayed area will receive a herbicide dose within $10 \%$ of the nominal application rate on only $17 \%$ of the total area, and within $30 \%$ of the application rate on $50 \%$ of the total area.

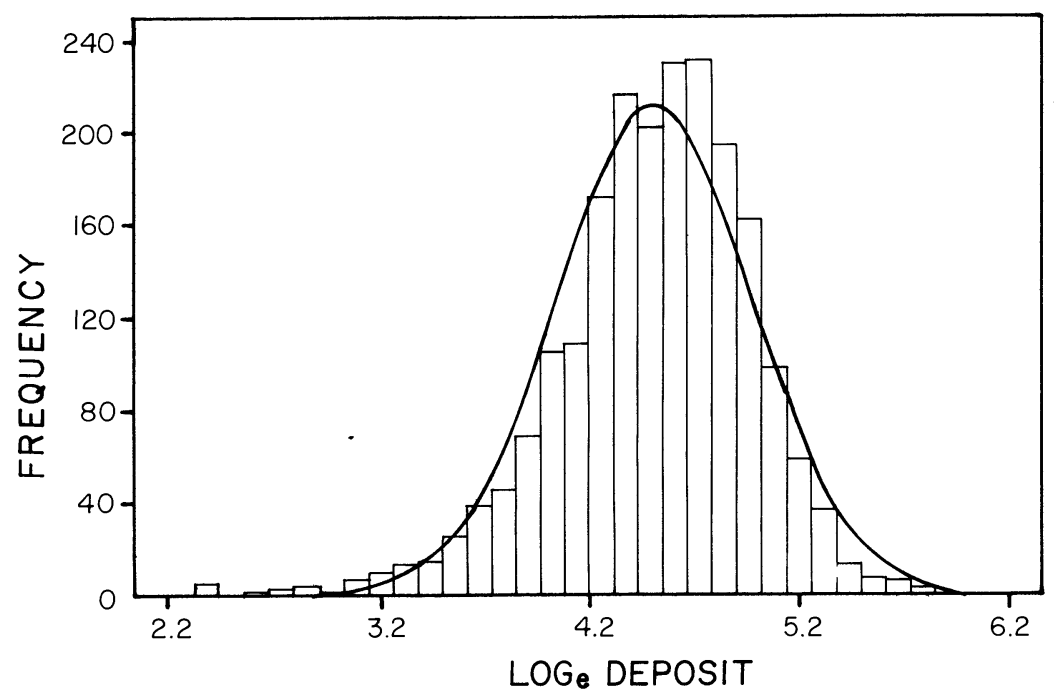

Figure 1: Following a logarithmic transformation, the distribution of spray deposits (bars) closely follows a normal distribution (line).

TABLE 1: Accuracy of flying as measured in two trials.

\begin{tabular}{lccccc}
\hline Aircraft & $\begin{array}{c}\text { Nominal lane } \\
\text { separation } \\
\text { (m) }\end{array}$ & $\begin{array}{c}\text { Actual lane } \\
\text { separation } \\
\text { range }\end{array}$ & $\begin{array}{c}\text { Mean } \\
\text { (m) }\end{array}$ & $\begin{array}{c}\text { S.D. } \\
\text { (m) }\end{array}$ & $\begin{array}{c}\text { C.V. }^{2} \\
\text { (\%) }\end{array}$ \\
\hline Squirrel $^{3}$ & 10.0 & 0 to 30 & 12.6 & 5.8 & 45.9 \\
AgCat $^{4}$ & 8.5 & -2 to 16 & 8.3 & 2.8 & 33.6 \\
Jet Ranger $^{4}$ & 10.0 & 3 to 16 & 10.1 & 3.5 & 34.7 \\
Squirrel $^{4}$ & 10.0 & 0 to 19 & 10.0 & 3.4 & 34.3 \\
\hline
\end{tabular}

${ }^{1}$ Standard deviation

${ }^{2}$ Coefficient of variation of distance between flight lines

$31.7 \mathrm{~km}$ block

${ }^{4} 1.0 \mathrm{~km}$ block

\section{Accuracy of flying}

Even with clearly visible markers at each end of the flight lines, neither fixed-wing aircraft nor helicopters could accurately maintain their position when passing over the centre of the experimental block (Table 1). There were no major differences between 
aircraft in flying accuracy with CVs for the distance between flight lines close to $34 \%$ for the $1 \mathrm{~km}$ long spray block. The CV was substantially increased (46\%) in the longer block. Windspeeds at $10 \mathrm{~m}$ above the ground varied between 2.7 and $13.6 \mathrm{~km} / \mathrm{h}$. Wind direction was approximately parallel to the flight line of the Jet Ranger and at $90^{\circ}$ to the flight lines of the other aircraft. There was no obvious relationship between windspeed, wind direction and deposit variation.

Flying speed

Crosswinds of between 11 and $28 \mathrm{~km} / \mathrm{h}$ were recorded during the speed measurement trials at Rotorua airport. There was no significant difference between the requested speed and the indicated airspeed (Table 2) which confirms that pilots are able, within reasonable limits, to maintain the speed indicated by their instruments. However, the indicated airspeed did not give a reliable measure of groundspeed and, as expected, the error in indicated airspeed was greatest at low flying speeds. The speed read from the radar device was in all cases very close to the calculated groundspeed.

TABLE 2: Various measures of flying speed observed during tests at Rotorua airport (Trial 1, Jet Ranger)

\begin{tabular}{cccc}
\hline $\begin{array}{c}\text { Requested } \\
\text { speed } \\
(\mathrm{km} / \mathrm{h})\end{array}$ & $\begin{array}{c}\text { Mean indicated } \\
\text { airspeed } \\
(\mathrm{km} / \mathrm{h})\end{array}$ & $\begin{array}{c}\text { Mean radar } \\
\text { speed } \\
(\mathrm{km} / \mathrm{h})\end{array}$ & $\begin{array}{c}\text { Mean calculated } \\
\text { groundspeed } \\
(\mathrm{km} / \mathrm{h})\end{array}$ \\
\hline $28 \mathrm{ab}^{1}$ & $24.5 \mathrm{a}$ & $36.6 \mathrm{~b}$ & $38.8 \mathrm{~b}$ \\
$56 \mathrm{a}$ & $53.2 \mathrm{a}$ & $60.5 \mathrm{~b}$ & $63.4 \mathrm{~b}$ \\
$83 \mathrm{a}$ & $84.2 \mathrm{ab}$ & $88.3 \mathrm{bc}$ & $91.7 \mathrm{c}$ \\
$111 \mathrm{a}$ & $111.7 \mathrm{a}$ & $110.3 \mathrm{a}$ & $115.3 \mathrm{a}$ \\
\hline
\end{tabular}

${ }^{1}$ Numbers in a row followed by the same letter are not significantly different $(P=0.05$, Fisher's Protected LSD test)

During the operational trial at Kaingaroa forest, there were significant differences between the requested and actual flying speed in all cases except the faster of the two Squirrel treatments (Table 3 ). In all cases the aircraft were flown faster than requested, the largest percentage error (22.6\%) occurring with the AgCat. This may be partly because the highest mean windspeed occurred during the AgCat runs $(13.6 \mathrm{~km} / \mathrm{h}$ cross wind), followed by the Jet Ranger $(7.1 \mathrm{~km} / \mathrm{h}$ parallel wind) and the Squirrel $(2.7 \mathrm{~km} /$ $\mathrm{h}$ cross wind). Compared with the mean flying speeds, the standard deviations were fairly low indicating that the pilots were flying at a relatively consistent speed over successive flight lines. Once again, this suggests poor quality instrumentation rather than lack of attention from the pilots.

TABLE 3: Requested and measured mean flying speed calculated during operational field trials (Trial 2).

\begin{tabular}{lccccr}
\hline Aircraft & $\begin{array}{c}\text { Flight line } \\
\text { length } \\
(\mathrm{m})\end{array}$ & $\begin{array}{c}\text { Requested } \\
\text { speed } \\
(\mathrm{km} / \mathrm{h})\end{array}$ & $\begin{array}{c}\text { Mean } \\
\text { measured } \\
\text { speed } \\
(\mathrm{km} / \mathrm{h})\end{array}$ & $\begin{array}{c}\mathrm{SD} \\
(\mathrm{km} / \mathrm{h})\end{array}$ & \% Error \\
\hline AgCat & 890 & $157 \mathrm{a}^{1}$ & $193 \mathrm{~b}$ & 7.6 & +22.6 \\
Jet Ranger & 870 & $83 \mathrm{a}$ & $91 \mathrm{~b}$ & 6.2 & +9.6 \\
Squirrel & 870 & $83 \mathrm{a}$ & $98 \mathrm{~b}$ & 3.0 & +18.1 \\
Squirrel & 870 & $111 \mathrm{a}$ & $113 \mathrm{a}$ & 3.4 & +1.4 \\
\hline
\end{tabular}

${ }^{1}$ Numbers in a column followed by the same letter are not significantly different ( $\mathrm{P}=0.05$, Fisher's Protected LSD test). 


\section{DISCUSSION}

To determine the proportion of the experimental block which receives a specific herbicide dose, the distribution of spray deposits must be known. It is important to consider the scale on which spray deposits are sampled in relation to the size of the weeds which are affected by the herbicide. To illustrate this, consider an extreme where spray deposited over one hectare was sampled. This would mask virtually all of the variability in the amount deposited on individual plants. At the other extreme, if deposits were estimated from square millimetre samples, variability between samples would be much higher than the variability in amounts deposited per plant. The scale of plant sizes varies from a few $\mathrm{cm}^{2}$ for small or young herbaceous and grass species, and seedlings in general, to $\mathrm{m}^{2}$ for woody species. Thus, the experimental methods described in this paper, with spray collectors mainly in the size range of 100$150 \mathrm{~cm}^{2}$, can be considered as a reasonable compromise in terms of sampling scale.

At this scale of sampling, a large database of spray deposit information has been used to show that after a log transformation, spray deposits closely approximate a normal distribution. The data reveal that high levels of deposit variation are typical following aerial herbicide application with, on average, only $17 \%$ of the spray block receiving a herbicide dose within $10 \%$ of the application rate. In relating these findings on deposit variability to effects on weeds, there are three important considerations; weed size, mode of action of the herbicide, and the shape of the dose-response curve of the herbicide on the weed. Large plants tend to collect a higher proportion of the spray and exhibit less deposit variation (Richardson et al. 1989, 1990) than small twodimensional collecting surfaces; thus as plant size increases, the variability between collectors used in these trials will become less important. Finally, with "flat" doseresponse curves, a large change in herbicide dose is required before there is a significant reduction in weed "kill", and the relative importance of between-sample variability again diminishes.

Prior to any spray operation, a representative swath pattern is usually determined, using computer simulation or experimental methods, so that the maximum lane separation with an acceptable CV can be calculated. These calculations assume that the aircraft runs are actually at the correct spacing i.e. there are no flying errors. However, results from the two trials investigating the accuracy of flying and a similar experiment conducted in the USA (Barry 1977), have shown that flying errors are a major source of spatial variability in spray deposition. This is true even on flat, uniform spray blocks where the start and end-points of each flight line have been accurately marked. Biological consequences of such levels of spatial variability must be evaluated and, if necessary, an appropriate margin of flying error should be allowed when calculating the optimum lane separation. One simple precaution, recommended by Parkin and Wyatt (1982), is to choose a lane separation value which corresponds to a flat section on a graph of lane separation versus CV. At this spacing, a small error in lane separation should not produce a large increase in CV. The lane separation distance will not necessarily be as large as one based on the criterion of a maximum acceptable CV of $30 \%$

Results from trials measuring flying speed indicate that although pilots are able to maintain a consistent airspeed, their instrumentation is far from ideal in terms of flying at the requested groundspeed. In the trial monitoring operational applications, the aircraft were consistently flown at speeds greater than those requested. Average errors close to $20 \%$ were observed on two occasions, the greatest being associated with a relatively high windspeed. Errors of this magnitude would result in serious underdosing. In practice, however, an experienced crew would probably realise that the aircraft was spraying too great an area for each tank load, and adjust the mixture accordingly. Better instrumentation, such as the radar speed measuring device (Franz 1991), is one simple solution to the problem. The ability of pilots to fly at a reasonably consistent airspeed suggests that with better instruments, the contribution of variation in flying speed to overall deposit variability would be minimal.

Of the factors considered, error in locating and maintaining the correct track along flight lines is probably the largest contributor to high levels of spatial variability of 
spray deposition. Flying height, wind speed and wind direction may also contribute to spatial variability. Although spraying with higher crosswind speeds will tend to increase the swath width and decrease deposit variation, the opposite will be true if either windspeed or direction is inconsistent. There is little scope for spraying herbicide with higher crosswind speeds because of the need to minimise spray drift. If aerial application practices are to be modified to meet the criterion of a maximum $\mathrm{CV}$ of $30 \%$, all major factors contributing to spatial variability must be considered. Probably the best options for minimising deposit variation are reduction of the lane separation and employment of some form of track guidance.

To determine the biological implications of high levels of spray deposit variation, the spray deposit distribution model must be linked to models that describe the response of the weed to the herbicide and the response of the crop to various levels of weed control. The costs and benefits of various techniques which affect variability in deposition (both positive and negative) can then be evaluated in terms of effects on the crop. Such calculations are currently in progress using methods similar to those described by Dorr and Pannell (1992).

\section{ACKNOWLEDGEMENTS}

The authors thank Mark Kimberley for advice on the analysis of spray deposition data and John Maber, Bob Moffat and Ruth Gadgil for useful comments on the manuscript.

\section{REFERENCES}

Barry, J.W., 1977. Problems associated with maintaining consistent swaths when spraying forests with helicopters. Agricultural Aviation 18: 18-22.

Dorr, G.J. and Pannell, D.J., 1992. Economics of improved spatial distribution of herbicide for weed control in crops. Crop. Prot. 11: 385-391.

Franz, E., 1991. On-board monitoring of ground speed and height-of-flight of agricultural aircraft. ASAE Paper No. AA91-004, St. Joseph, MI, 49085-9659, USA.

Parkin, C.S. and Wyatt, J.C., 1982. The determination of flight-lane separations for the aerial application of herbicides. Crop Prot. 1: 309-321.

Richardson, B., Ray, J., and Vanner, A., 1989. Evaluation of techniques to measure aerial spray deposition. Proc. 42nd N.Z. Weed and Pest Control Conf:: 132-136.

Richardson, B., Ray, J., and Vanner, A., 1990. Factors affecting spray deposition following the aerial application of herbicides. Proc. 9th Australian Weeds Conf. J.W. Heap (Ed.), Adelaide, S.A.: 309-312.

Spillman, J.J., 1980. The efficiency of aerial spraying. AeronauticalJ. Royal Aeronautical Soc. February: 60-69.

Zar, J.H., 1984. Biostatistical Analysis, 2nd edition. Prentice-Hall International, Inc., New Jersey. 